\title{
An unexpected cyclization reaction of tert-butyl o-trimethylsilylphenyl sulfoximine
}

\author{
Jörg Christoph Schmidt, ${ }^{a}$ Gunadi Adiwidjaja, ${ }^{b}$ and Ernst Schaumann ${ }^{\text {a* }}$ \\ ${ }^{a}$ Institut für Organische Chemie, Clausthal Univ. of Technology, Leibnizstraße 6, \\ 38678 Clausthal-Zellerfeld, Germany \\ ${ }^{b}$ Mineralogisch-Petrographisches Institut, University of Hamburg, Grindelallee 48, \\ 20146 Hamburg, Germany \\ E-mail: Ernst.schaumann@tu-clausthal.de
}

Dedicated to Rainer Beckert on the occasion of his $60^{\text {th }}$ anniversary

\begin{abstract}
An efficient one-pot synthesis of the title compound $\mathbf{5}$ starting from methyl phenyl sulfoximine is described. On attempted iododesilylation of this compound using iodine chloride, one methyl group on the silicon atom is formally replaced by the imino nitrogen to give a derivative $\mathbf{8}$ of the novel heterocyclic system 1,3,2-benzothiasilazole.
\end{abstract}

Keywords: Silylation, imination, demethylation, silyl migration, oxidative ring closure

\section{Introduction}

Recently, sulfoximines with two different organyl groups have attracted wide attention because of their inherent chirality. Thus, optically active derivatives are employed as auxiliaries in diastereoselective synthesis or as ligands in metal-catalyzed enantioselective transformations. ${ }^{1}$ We were interested in the synthesis of a sulfoximine-based hypervalent iodine reagent such as an adequately modified Dess-Martin reagent. ${ }^{2}$ We here report on a surprising reaction encountered en route to our target compounds.

\section{Results and Discussion}

An apparent intermediate for the synthesis of a sulfoximine-modified Dess-Martin reagent appears to be tert-butyl $o$-iodophenyl sulfoximine 6 (Scheme 2). This compound was synthesized starting from methyl phenyl sulfoximine $\mathbf{1}$ which is readily available in an optically active form. ${ }^{3}$ 
In a reported synthesis of target compound $\mathbf{6}^{4}$ the sulfoximine $\mathbf{1}$ is silylated by bis(trimethylsilyl)acetamide or more conveniently by diethyl(trimethylsilyl)amine ${ }^{5}$ in acetonitrile to give the $N$-silyl derivative 2 (Scheme 1). Subsequently, the tert-butyl group of $\mathbf{3}$ is developed by three consecutive deprotonation/methylation steps at the $\mathrm{CH}$ acidic $\alpha$-position. As the $N$-silyl group is lost on work-up, the $\mathrm{N}$-silylation step has to be repeated to yield the $N$-silyl sulfoximine 4. The sulfoximine unit in $\mathbf{4}$ is an excellent ortho-director of lithiation. ${ }^{4,6}$ This is seen on addition of butyl lithium to sulfoximine 4 which apparently leads to formation of the $o$-lithio derivative. In the absence of an electrophile, this carbanion is silylated intramolecularly by 1,4-transfer of the trimethylsilyl group from nitrogen to carbon yielding the o-trimethylsilyl derivative 5 (Scheme 1).

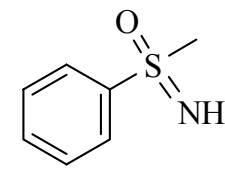

1<smiles>[Y][C@H](C)[R10]#[R]</smiles><smiles>CS(=O)(=O)N=S(C)(C)=O</smiles>

2
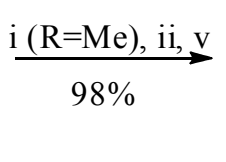

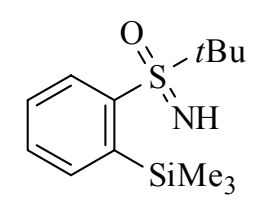

5
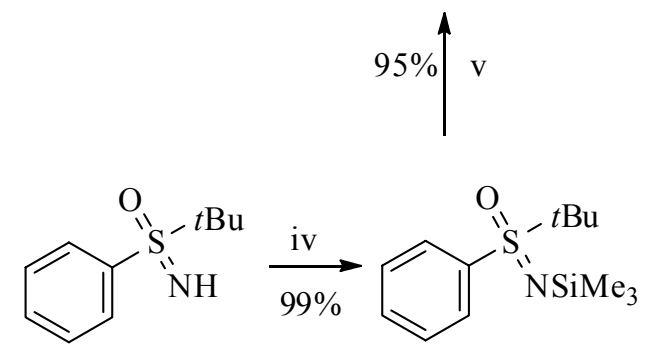

3

4

Scheme 1. Syntheses of tert-butyl $o$-trimethylsilylphenyl sulfoximine. i) $\mathrm{R}_{2} \mathrm{NSiMe}_{3}$ (1.2 eq); ii) 3 $\times\left[n\right.$-BuLi (1 eq), THF, $\left.0{ }^{\circ} \mathrm{C}, 10 \mathrm{~min} / \mathrm{MeI}(1.0 \mathrm{eq}), 20 \mathrm{~min}\right]$; iii) $\mathrm{MeOH}, 2 \mathrm{~h}, 20{ }^{\circ} \mathrm{C}$; iv) $\operatorname{HMDS}(5$ eq.), $85^{\circ} \mathrm{C}, 40 \mathrm{~min}$; v) $n$-BuLi (1.0 eq), THF, $-78->0{ }^{\circ} \mathrm{C}$.

We envisaged a more direct synthesis of product 5 which provides this compound starting from sulfoximine 1 in a one-pot procedure (Scheme 1). In fact, imination of 1 with dimethyl(trimethylsilyl)amine, build-up of the tert-butyl group, and finally $o$-deprotonation yields product 5 in almost quantitative yield (Scheme 1) compared to an overall yield of $82 \%$ following the earlier multistep approach. ${ }^{4,5}$ The use of dimethyl(trimethylsilyl)amine rather than the analogous diethyl compound ${ }^{5}$ has the advantage of producing the more volatile and so more easily removed dimethylamine as parallel product in the silylation step.

On $o$-deprotonation of sulfoximine 4 and quenching with iodine, the $o$-iodo derivative $\mathbf{6}$ is reported to be available in $75 \%$ yield along with some $o$-silyl sulfoximine $\mathbf{5}$. However, in our hands for unknown reasons this reaction did not provide iodo derivative $\mathbf{6}$, but only $\mathbf{5}$ as a result of the silyl shift. But having $o$-silyl compound 5 in hand, an iododesilylation ${ }^{7}$ approach to 6 seemed to offer an attractive alternative (Scheme 2). However, when $\mathbf{5}$ is treated with iodine 
chloride, the product is not the expected iodide $\mathbf{6}$, but a totally different type of product which was identified as the $3 H-1 \lambda^{6}, 3,2$-benzothiasilazole 1-oxide 8 by a single-crystal X-ray investigation (Figure 1). To the best of our knowledge, this is the first example of a 1,3,2benzothiasilazole.

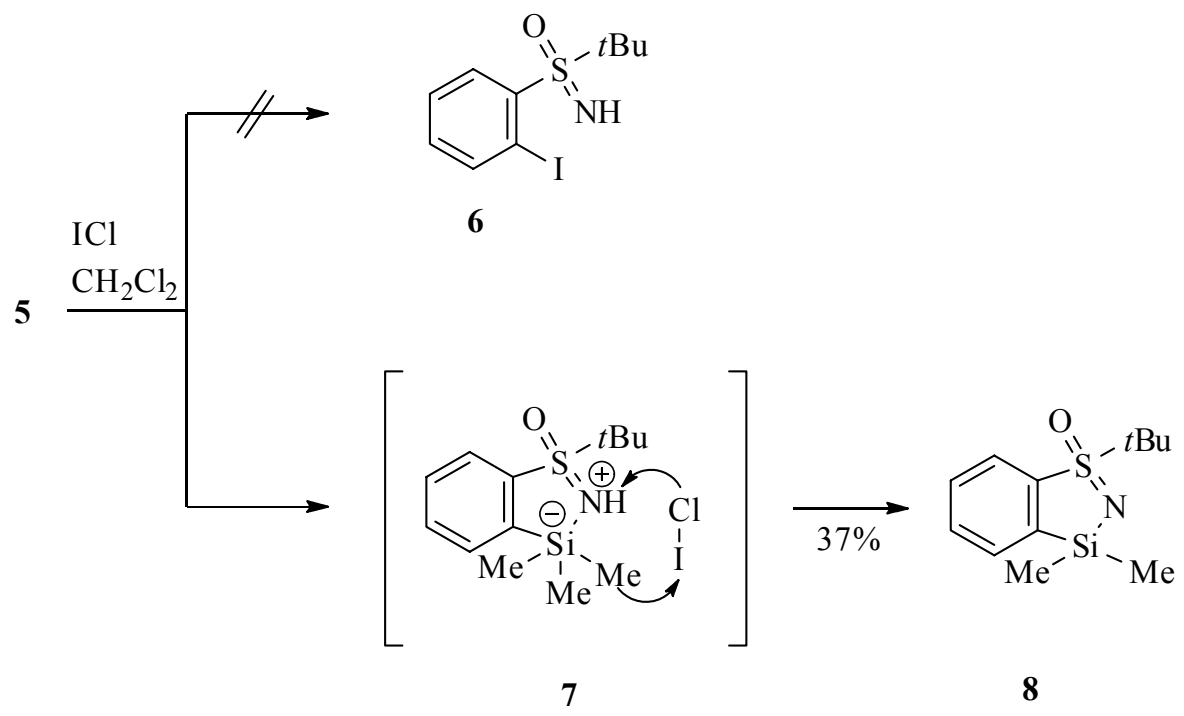

Scheme 2. Cyclization of sulfoximine 5 to 1-tert-butyl-3,3-dimethyl-3H-1 $\lambda^{6}, 3,2-$ benzothiasilazole 1-oxide $(\mathbf{8})$.

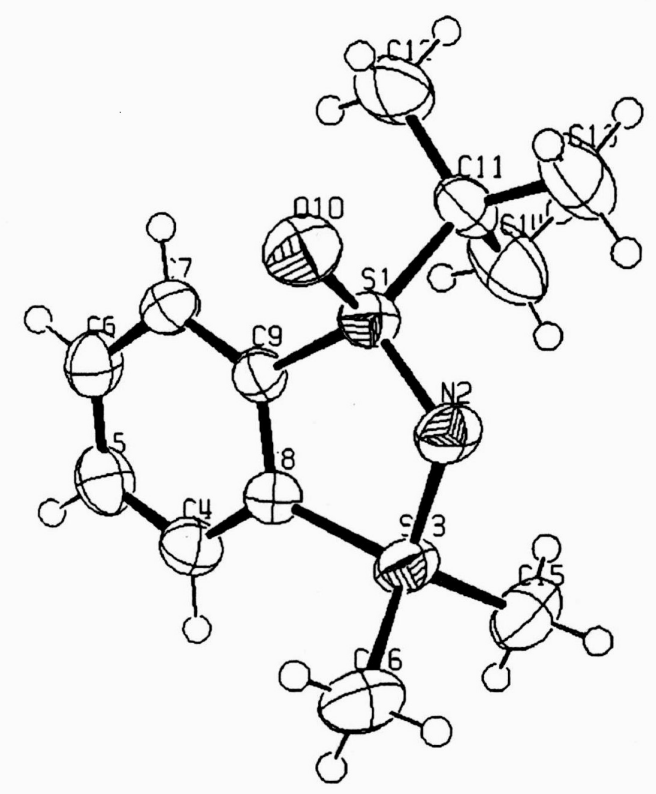

Figure 1. ORTEP drawing of compound 8 with salient bond lengths $[\AA]$ : S1-O10 1.451, S1-N2 1.512, S1-C9 1.792, S1-C11 1.828, Si3-N2 1.721, Si3-C8 1.886. 
The cyclization of $\mathbf{5}$ to $\mathbf{8}$ occurs formally with extrusion of methane. However, we assume an initial formation of a nitrogen-silicon bond giving the hypervalent silicon species 7 (Scheme 2). From here, demethylation by the iodonium cation leads to product $\mathbf{8}$ in a reasonable manner. Comparable cyclization reactions have been reported for the action of iodine on a $\beta$ trimethylsilyl substituted acrylate ${ }^{8}$ and as result of an intramolecular alkoxide attack also invoking hypervalent silicon intermediates. ${ }^{9,10}$ For highly acidic $o$-trimethylsilyl $\alpha$-trifluoromethyl benzyl alcohols the cyclization occurs spontaneously in polar aprotic solvents with extrusion of hydrocarbons. ${ }^{11}$ However, this type of reaction was not observed when the title compound 5 was heated in DMSO or acetonitrile. While these literature examples involve formation of a favored silicon-oxygen bond, we recently reported an example of methyl loss from silicon with formation of a silicon-carbon bond. ${ }^{12}$ In contrast, the cyclization of $\mathbf{5}$ to $\mathbf{8}$ is noteworthy as it leads to the formation of a relatively weak silicon-nitrogen bond.

As the sulfoxide moiety is known to assist in $o$-deprotonation, ${ }^{13,14}$ the action of base on $\mathbf{8}$ was studied. However, no carbanion formation in the 7 position could be detected. With LDA at $-78{ }^{\circ} \mathrm{C}$, complete decomposition of the thiasilazole 8 occurred. Also tert-butyllithium apparently did not attack the 7-H position, but rather seems to cleave the Si-N bond in 8 giving the $o$ TBDMS congener of $\mathbf{5}$ which however could not be fully characterized.

\section{Acknowledgements}

We gratefully appreciate the skilful assistance of Mrs. Monika Ries.

\section{Experimental Section}

General. ${ }^{1} \mathrm{H}$ NMR and ${ }^{13} \mathrm{C}$ NMR spectra were recorded on a Bruker Avance DPX 200 instrument in $\mathrm{CDCl}_{3}$ as solvent. Chemical shifts were measured in $\delta$ (ppm) and coupling constants $J$ in Hz. TMS $(\delta=0.00)$ or the signal of the solvent $\left(\mathrm{CDCl}_{3}: \delta=7.26 \mathrm{ppm}\right)$ served as internal standard in ${ }^{1} \mathrm{H}$ NMR spectra. The solvent peak $\left(\mathrm{CDCl}_{3}\right.$ at $\left.\delta=77.0 \mathrm{ppm}\right)$ was used as reference for ${ }^{13} \mathrm{C}$ spectra. MS were recorded on a Hewlett-Packard 5989B instrument. ESI-MS spectra were recorded on a Hewlett Packard/Kayak XA instrument LC-MSD Series 1100. IR spectra were recorded on a Bruker Vektor 22 FT-IR spectrometer. All solvents were distilled before use.

Methyl phenyl sulfoximine (1) was obtained from methyl phenyl sulfoxide by imination with 4nitrobenzenesulfonamide / iodosylbenzene with catalysis by iron(III) acetylacetonate, and subsequent removal of the sulfonyl unit by treatment with cesium carbonate/thiophenol. ${ }^{15}$

tert-Butyl o-trimethylsilylphenyl sulfoximine (5) was obtained by combining the individual steps of the published procedures ${ }^{4 \mathrm{~b}, 5}$ in a one-pot protocol. Thus, sulfoximine 1 (172 $\mathrm{mg}, 1.1$ 
mmol) in dry THF (3 mL) was mixed with dimethyl(trimethylsilyl)amine (0.23 mL, $1.44 \mathrm{mmol})$ and the mixture stirred at $\mathrm{rt}$ for $1.5 \mathrm{~h}$. $\mathrm{N}_{2}$ gas was blown through the solution to drive off $\mathrm{Me}_{2} \mathrm{NH}$ to give finally a viscous oil which was briefly exposed to 0.1 Torr pressure. The residue (252 $\mathrm{mg}$ ) was dissolved in dry THF $(3 \mathrm{~mL})$ and $\mathrm{BuLi}(0.75 \mathrm{~mL}, 1.6 \mathrm{M}$ in hexane, $1.2 \mathrm{mmol})$ was added dropwise at $0{ }^{\circ} \mathrm{C}$. To the yellow mixture $\mathrm{MeI}(0.075 \mathrm{~mL}, 1.2 \mathrm{mmol})$ was added at $\mathrm{rt}$ and the mixture stirred for $30 \mathrm{~min}$. At this point, ${ }^{1} \mathrm{H}$ NMR spectroscopy showed clean formation of an Et unit. The treatment with BuLi and MeI was repeated twice under identical conditions and again with control by NMR spectroscopy to confirm finally formation of a $t \mathrm{Bu}$ unit. The mixture was then cooled to $-78{ }^{\circ} \mathrm{C}$ and $\mathrm{BuLi}(0.82 \mathrm{~mL}, 1.6 \mathrm{M}$ in hexane, $1.3 \mathrm{mmol})$ added dropwise. After stirring at $0{ }^{\circ} \mathrm{C}$ for $1 \mathrm{~h}$, aq. $\mathrm{NH}_{4} \mathrm{Cl}$ solution $(5 \mathrm{~mL})$ was added to the reaction mixture and the organic product extracted by washing with $\mathrm{CH}_{2} \mathrm{Cl}_{2}(3 \times 10 \mathrm{~mL})$. The combined organic phases were dried $\left(\mathrm{MgSO}_{4}\right)$. After filtration, the solvents were evaporated in vacuo to give 5 (291 mg, 98\%). The compound data were identical with the published values. ${ }^{4 \mathrm{~b}}$

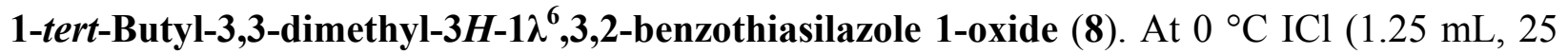
mmol) was slowly added to a solution of $5(6.75 \mathrm{~g}, 25 \mathrm{mmol})$ in dry $\mathrm{CH}_{2} \mathrm{Cl}_{2}(150 \mathrm{~mL})$. After stirring at this temperature for $1 \mathrm{~h}$, sat. aq. $\mathrm{Na}_{2} \mathrm{~S}_{2} \mathrm{O}_{3}$ solution $(100 \mathrm{~mL})$ was added. The phases were separated and the aq. phase extracted with $\mathrm{CH}_{2} \mathrm{Cl}_{2}(3 \times 50 \mathrm{~mL})$. The combined organic phases were dried $\left(\mathrm{Na}_{2} \mathrm{SO}_{4}\right)$ and the crude product 8 recrystallized from hexanes/EtOAc. Yield $1.95 \mathrm{~g}(37 \%)$ as colorless crystals. $\mathrm{Mp} 137{ }^{\circ} \mathrm{C} .{ }^{1} \mathrm{H}$ NMR $(200 \mathrm{MHz})$ in $\mathrm{CDCl}_{3}: \delta 7.90-7.80(\mathrm{~m}$, 1H), 7.75-7.68 (m, 1H), 7.65-7.49 (m, 2H), 1.41 (s, 9H), 0.44, 0.43 (each s, 3H). $-{ }^{13} \mathrm{C} \mathrm{NMR} \mathrm{(50}$ $\mathrm{MHz}, \mathrm{CDCl}_{3}$ ): $\delta 145.0$ (quat.), 142.9 (quat.), 130.4 (tert.), 130.1 (tert.), 128.0 (tert.), 124.4 (tert.), 59.9 (quat.), 24.1 (prim.), 1.5 (prim.), -0.4 (prim.). - IR (KBr): 2969, 2933, 1445, 1253, 1223, $1135,1105,1082,1039,1024,860,824,801,787,762,720,694,634,513 .-\mathrm{MS}(70 \mathrm{eV}): \mathrm{m} / \mathrm{z}=$ 254 (1) [M+H], 197 (14), 181 (69), 166 (100), 84 (49). - ESI-MS m/z = 529 (100 [M + 2 Na]. Anal. Calc. For $\mathrm{C}_{12} \mathrm{H}_{19}$ NOSSi: C, 56.87; H, 7.56; N, 5.53; S, 12.65. Found: C, 56.46; H, 7.46; N, 5.52; S, 13.02\%.

Crystal structure determination of heterocycle (8). ${ }^{16}$ Appropriate crystals were obtained by crystallization from cyclohexane. The size of the actual crystal was $0.31 \times 0.27 \times 0.22 \mathrm{~mm}^{3}$. Intensity data were collected with a CAD 4-SDP single-crystal diffractometer (Enraf-Nonius) using graphite-monochromated $\mathrm{Cu}-\mathrm{K}_{\alpha}$ radiation. The final refinement was based on 3192 symmetry-independent reflections with $\mathrm{I}>3 \sigma$. The structure was solved by the direct-methods program MULTAN. The $E$ map revealed the position of all the heavy atoms. Convergence was achieved at $R=0.0437\left(R_{w}=0.1016\right) .-\mathrm{C}_{12} \mathrm{H}_{19} \mathrm{NOSSi}, \mathrm{M}_{\mathrm{r}}=253.3$, monoclinic, $a=9.244(1), b$ $=16.726(1), c=13.352(1) \AA, \beta=137.27(1)^{\circ}, V=1400.8(2) \AA^{3}, T=$ room temp., space group $P 2_{1} / \mathrm{c}, Z=4, \mathrm{~d}_{\text {cal. }} 1.202 \mathrm{~g} \mathrm{~cm}^{-1}$. 


\section{References}

1. (a) Pyne, S. G. Sulfur Rep. 1999, 21, 281. (b) Reggelin, M.; Zur, C. Synthesis 2000, 1. (c) Chemla, F. J. Chem. Soc., Perkin Trans. 1 2002, 275. (d) Harmata, M. Chemtracts 2003, 16, 660. (e) Okamura, H.; Bolm, C. Chem. Lett. 2004, 33, 482. (f) Gais, H. J. Heteroat. Chem. 2007, 18, 472.

2. Muirhead-Hofmann, K.; Reeve, T. B.; Russell, A. G.; Smith, M. H.; Weston, M.; White, M. J. Science of Synthesis, Reagents: Oxidation; Carreira, E. M.; Decco, C. P.; Fürstner, A.; Molander, G. A.; Reider, P. J.; Schaumann, E.; Shibasaki, M.; Thomas, E. J.; Trost, B. M., Eds.; Thieme: Stuttgart, 2010; Vol. 2010/5, p 177.

3. Brandt, J.; Gais, H.-J. Tetrahedron Asymmetry 1997, 8, 909.

4. (a) Levacher, V.; Langer Eriksen, B.; Begtrup, M.; Dupas, G.; Quéguiner, G.; Duflos, J.; Bourguignon, J. Tetrahedron Lett. 1999, 40, 1665. (b) Gaillard, S.; Papamicaël, C.; Dupas, G.; Marsais, F.; Levacher, V. Tetrahedron 2005, 61, 8138.

5. K.-J. Hwang, J. Org. Chem. 1986, 51, 99.

6. Wessels, M.; Mahajan, V.; Bosshammer, S.; Raabe, G.; Gais, H.-J. Eur. J. Org. Chem. 2011, 2431.

7. Félix, G.; Dunoguès, J.; Pisciotti, F.; Calas, R. Angew. Chem. 1977, 89, 502; Angew. Chem., Int. Ed. Engl. 1977, 16, 4888.

8. Shindo, M.; Matsumoto, K.; Shishido, K. Angew. Chem. 2003, 116, 106; Angew. Chem., Int. Ed. Engl. 2004, 43, 104.

9. Kirmse, W.; Söllenböhmer, F. J. Chem. Soc., Chem. Commun. 1989, 774.

10. Kumar Tipparaju, S.; Mandal, S. K.; Sur, S.; Puranik, V. G.; Sarkar, A. Chem. Commun. $2002,1924$.

11. Yamamoto, Y.; Takeda, Y.; Akiba, K. Tetrahedron Lett. 1989, 30, 725. See also: Fitch III, J. W.; Cassidy, P. E., Jamil Ahamed, M. J. Organomet. Chem. 1996, $522,55$.

12. Schaumann, E.; Kirschning, A. J. Chem. Soc., Perkin Trans. 1 1990, 419.

13. Quesnelle, C.; Iihama, T.; Aubert, T.; Perrier, H.; Snieckus, V. Tetrahedron Lett. 1992, 33, 2625.

14. Furukawa, N.; Shibutani, T.; Fujihara, H. Tetrahedron Lett. 1989, $30,7091$.

15. Mancheño, O. G.; Bolm, C. Chem. Eur. J. 2007, 13, 6674.

16. Crystallographic data (excluding structure factors) for the structure reported in this paper have been deposited with the Cambridge Crystallographic Data Centre as supplementary publication no. CCDC-845587. The data can be obtained free of charge from the CCDC, via www.ccdc.cam.ac.uk/data_request/cif 